\title{
Cyclooxygenase-2 Inhibitors in Gynecologic Practice
}

Thomas P. Connolly, DO, Department of Obstetrics and Gynecology, Marshfield Clinic-Wausau Center, Wausau, Wisconsin

\begin{abstract}
Treatment of pain and inflammation associated with dysmenorrhea, endometriosis, ovarian cancers and operative procedures is an ongoing challenge in gynecology. Understanding the roles of prostanoids and estrogen in these conditions and appropriate treatment approaches have advanced beyond traditional nonsteroidal anti-inflammatory drugs. In this article, the author describes some of the basic mechanisms of nonspecific nonsteroidal anti-inflammatory drugs and newer cyclooxygenase-2 inhibitors, especially as they are used in the obstetrics/gynecology practice.
\end{abstract}

\section{INTRODUCTION}

Nonsteroidal anti-inflammatory drugs (NSAIDs) are often the first choice of treatment for acute myalgias, orthopedic injuries, postoperative pain, chronic rheumatoid arthritis, and osteoarthritis. ${ }^{1}$ The newest class of NSAIDs, cyclooxygenase (COX) inhibitors, is being promoted heavily by the pharmaceutical industry. By the end of 1999, their first year on the market, sales in the United States skyrocketed to $\$ 472$ million for rofecoxib and $\$ 1.4$ billion for celecoxib. As newer NSAIDs and other alternatives become available, the practicing clinician needs to be fully aware of the therapeutic choices in specific applications. The purpose of this review is to provide a brief overview of COX-2 inhibitors that target the modulation of prostaglandin levels, especially in reference to gynecological applications.

\section{REPRINT REQUESTS:}

Thomas P. Connolly, DO

Department of Obstetrics and Gynecology

Marshfield Clinic-Wausau Center

2727 Plaza Drive

Wausau, WI 54401

Telephone: 715-847-3191

Fax: 715-389-3808

Email: connolly.thomas@mashfieldclinic.org

\section{KEYWORDS:}

Nonsteroidal anti-inflammatory drugs; Cyclooxygenase inhibitors; Endometriosis; Dysmenorrhea; Ovarian cancer; Perioperative pain; Inflammation 


\section{Prostaglandins}

Prostaglandins are ubiquitous fatty-acid derivatives that serve as autocrine/paracrine mediators involved in inflammation and immune response modulation, renal function, vasomotor tone, platelet aggregation and blood clotting, differentiation of immune cells, wound healing, nerve growth, bone metabolism, ovulation and initiation of labor.

Tissue damage activates phospholipase A2, causing arachidonic acid to be cleaved from cell membrane phospholipids. Upon release, arachidonic acid can proceed down either the lipoxygenase pathway leading to the formation of leukotrienes and lipoxins, or the COX pathway leading to the formation of thromboxanes and prostaglandins.

Cyclooxygenase occurs in two isoforms, COX-1 and COX2. COX-1 is present in most tissues, and maintains normal gastric mucosa and influences kidney and platelet function. ${ }^{1}$ COX-2 is not present at baseline in most tissues. Exceptions include the central nervous system, the gastrointestinal tract, kidneys, bones, ovaries and uterus. COX-2 is inducible by pro-inflammatory cytokines and produces prostaglandins that mediate the inflammatory and pain responses. ${ }^{1}$ Its inhibition is a therapeutic goal. COX-1 and COX-2 are products of two genes residing on different chromosomes. Both attach to different sites on arachidonic acid, but convert it to prostaglandins equally efficiently. Glucocorticoids inhibit the induction of COX-2, but do not affect COX-1 activity and baseline prostaglandins levels.

At sites of inflammation, transcription and de novo synthesis of COX-2 are triggered by exposure of inflammatory cells to endotoxin, interferon and cytokines. Hyperalgesic and proinflammatory prostaglandins are generated. In the stomach, COX-1 catalyzes the synthesis of prostaglandin E-2 (PGE-2) and prostaglandin $\mathrm{I}-2$. These have cytoprotective actions and help in maintaining gastroduodenal mucosa integrity. Inhibition of COX-1 enzymes reduces these cytoprotective effects, and can lead to gastric bleeding and ulceration.

\section{Traditional NSAIDs}

NSAIDs have been in use long before anything was known about their mechanism of action (table 1). Traditional NSAIDs inhibit both COX-1 and COX-2, and in so doing not only decrease inflammation and pain, but also promote gastrointestinal tract damage and bleeding. Inhibitory potency and selectivity of conventional first-generation NSAIDs for COX-1 and COX-2 vary greatly. However, at therapeutic concentrations none of the currently marketed NSAIDs spare gastric COX-1 activity.

\section{Side effects of traditional NSAIDs}

It is estimated that $25 \%$ of patients using NSAIDs experience some kind of side effect, with 5\% developing serious health consequences (massive GI bleeds, acute renal failure, etc.). Trials have been pursued to identify which patients are at high risk for NSAID-associated gastrointestinal disorders. The occurrence of side effects varies with the NSAID. Racemic ibuprofen and dexibuprofen showed a 30\% and diclofenac a $90 \%$ higher incidence of adverse drug reactions. ${ }^{2}$ Proton pump inhibitors and NSAIDs have been coadministered in an attempt to improve gastrointestinal safety. Prolongation of wound healing can be worrisome as well. Acute renal failure can arise as a side effect of NSAID usage, especially in a subset of patients in a state of volume depletion.

\section{The first-generation $\mathrm{COX}-2$ inhibitors}

Inhibitors specific for COX-2 should have less gastrointestinal toxicity than other less selective NSAIDs (table 2). Two medications that predominantly inhibit only COX-2, rofecoxib and celecoxib, are currently available by prescription in the United States.

Table 1. History of prostaglandin E pharmacotherapy.

\begin{tabular}{ll}
\hline Date & Breakthrough \\
\hline Ancient times & Parts of the willow tree used to relieve pain and inflammation \\
1897 & Acetylsalicylic acid isolated, identified and synthesized \\
1899 & Bayer Company first marketed aspirin \\
1963 & Indomethacin synthesized, followed by several other synthetic and semisynthetic NSAIDs \\
Mid-1970s & Investigations into development of aromatase inhibitors begins \\
1971 & NSAIDs such as aspirin exert their actions primarily by inhibiting the production of prostaglandins \\
1976 & COX enzyme purified \\
1984 & COX enzyme shown to increase in inflamed tissue \\
1988 & COX enzyme shown to be stimulated by interleukin-1 \\
1988 & COX enzyme cloned \\
1990 & COX shown to be induced by endotoxin and prevented by glucocorticoids, but dexamethasone does not \\
1991 & affect baseline prostaglandin formation, so postulated a second COX enzyme \\
1999 & Second COX gene discovered and isoform cloned: COX-2 \\
2002 & Launch of COX-2 selective inhibitors: rofecoxib and celecoxib \\
\hline COX, cyclooxygenase & Second-generation COX-2 selective inhibitors: valdecoxib, parecoxib and etoricoxib \\
NSAID, nonsteroidal anti-inflammatory drugs
\end{tabular}


Table 2. Overview of cyclooxygenase modulating medications.

\begin{tabular}{cc}
\hline NSAIDS & $\begin{array}{c}\text { Cyclooxygenase-2 } \\
\text { inhibitors }\end{array}$ \\
\hline I. Acidic & I. First generation \\
A. Carboxylic acids & A. Celecoxib \\
1. Fenamic acids & B. Rofecoxib \\
a) meclofenamate & II. Second generation \\
2. Acetic acids & A. Valdecoxib \\
a) sulindac & B. Etoricoxib \\
b) indomethacin & C. Parecoxib \\
c) tolmetin & \\
d) diclofenac & \\
e) ketorolac & \\
3. Pyranocarboxylic & \\
acids & \\
a) etodolac & \\
4. Propionic acids & \\
a) naproxen & \\
b) flurbiprofen & \\
c) ibuprofen \\
d) ketoprofen & \\
5. Salicylic acids & \\
a) aspirin & \\
b) salsalate & \\
c) diflunisal & \\
B. Enolic acids & \\
1. Oxicams & \\
a) piroxicam & \\
1. Nabumetone & \\
\hline Nophthylalkanones & \\
\hline . & \\
\hline
\end{tabular}

Celecoxib is 375 times more selective for COX-2 than COX1 , and does not inhibit COX-1 at therapeutic doses. ${ }^{1}$ It is rapidly and completely absorbed following oral ingestion, even in the presence of food. Steady blood levels are achieved after 10 days. Celecoxib is metabolized by the liver to inactive metabolites that are excreted in the gut and urine. Its breakdown is slowed by fluconazole, which is metabolized by the same enzyme. It contains a sulfa molecule, so should be given with caution to patients with a history of sulfa allergy. In general, celecoxib is associated with a markedly lower rate of gastroduodenal injury, is safe and effective in the treatment of osteoarthritis, rheumatoid arthritis, and familial adenomatous polyposis, and results in the relief of acute pain and inflammation with less risk of renal toxicity. It is not recommended during the third trimester of pregnancy because it may cause congenital heart damage to the fetus.

Rofecoxib is completely absorbed when taken by mouth. Absorption is not influenced by food in the stomach. It is metabolized in the liver, but by a slightly different mechanism. It has been approved for primary dysmenorrhea, acute pain after dental and orthopedic surgery, fever, and pain and inflammation in osteoarthritis and rheumatoid arthritis. ${ }^{3}$ In clinical trials, gastrointestinal toxicity, including mucosal damage, perforation, ulcers and bleeding, occurred significantly less often with rofecoxib than ibuprofen, naproxen or diclofenac. ${ }^{3}$ It does not affect bleeding time and platelet aggregation, but has no advantage in terms of renal toxicity.

\section{The second-generation $\mathrm{COX}-2$ inhibitors}

Valdecoxib is a second-generation COX-2 inhibitor. ${ }^{4}$ It has improved potency and a broader therapeutic range than other COX-2 inhibitors, including celecoxib, and has a potential for once-daily dosing. It is the first, second-generation oral COX-2 specific inhibitor approved by the United States Federal Drug Administration for use in the treatment of dysmenorrhea, osteoarthritis and rheumatoid arthritis. In Europe, another second-generation COX-2 specific inhibitor, etoricoxib, is available. Due to the poor water solubility of valdecoxib, the prodrug, parecoxib, is being developed as an injectable valdecoxib for post-operative pain. ${ }^{4}$ In general, these second-generation COX-2 inhibitors exhibit improved gastrointestinal safety, are longer lasting, and are more effective at pain and inflammation control.

\section{Side effects of COX-2 inhibitors}

Several large, randomized, multicenter, placebo-controlled, double-blind trials have now confirmed that celecoxib is efficacious in pain relief (especially rheumatoid arthritis) while not affecting COX-1 activity in the gastrointestinal tract mucosa as evidenced by less frequent incidence of endoscopic ulcers compared with conventional NSAIDs. 5,6 However, the most common side effect of both rofecoxib and celecoxib has been the development of dyspepsia with no correlation to gastric ulcers or blood loss.

Concern has been expressed that COX-2 inhibitors may increase the risk of cardiovascular thromboembolic events (myocardial infarction, stroke, cardiovascular deaths, and peripheral events, such as hypertension, edema and congestive heart failure) because of their inhibition of vascular prostacyclin synthesis and lack of an effect on platelet thromboxane $\mathrm{A}(2)$ production and aggregation. However, the Celecoxib Long-term Arthritis Safety Study, a large randomized trial comparing celecoxib to ibuprofen or diclofenac while correcting for prophylactic acetylsalicylic acid use, showed that there was no increased risk of serious cardiovascular thromboembolic events associated with celecoxib compared with conventional NSAIDs. ${ }^{7}$

There is an intrarenal expression of COX-2 within the macula densa of the kidney that increases with salt restriction. ${ }^{8}$ In COX-2 allele knockout mice, severe renal problems arise, especially in relation to the stimulation of renin expression caused by a low-salt diet. ${ }^{9}$ In a randomized, controlled trial in elderly persons receiving a low-salt diet, it has been shown that the effects of rofecoxib COX-2 inhibition on renal function were similar to those observed with nonselective NSAIDs (indomethacin). ${ }^{10,11}$ Others, however, have reported that COX-2 inhibition in healthy elderly subjects may spare renal hemodynamic function, although the effects on sodium excretion, as well as urinary prostaglandin E2 and 6-keto-prostaglandin F1 alpha excretion, appear to be 
similar to those of nonspecific COX inhibitors, such as naproxen. ${ }^{12}$ Other manifestations of sodium retention (such as pleural effusions) have been reported with the use of rofecoxib. ${ }^{13}$

In general, it is the consensus that COX-2 selective inhibitors, like other NSAIDs, must be used cautiously or not at all in patients with predisposing diseases such as chronic renal failure, severe cardiac disease, and hepatic failure. ${ }^{14}$

\section{Dysmenorrhea}

Primary dysmenorrhea is characterized by painful uterine contractility caused by a hypersecretion of endometrial prostaglandins. ${ }^{15}$ NSAIDs are the treatment of first choice. Many clinical trials (controlled and uncontrolled) have demonstrated the efficacy of NSAIDs, such as the fenamates (meclofenamate), arylacetic acid derivatives (bromfenac, diclofenac) and arylpropionic acid derivatives (naproxen, ibuprofen, ketoprofen) in relieving primary dysmenorrhea. ${ }^{16-19}$ Valdecoxib demonstrates analgesic efficacy for treating women with primary dysmenorrhea, based on onset, magnitude, and duration of analgesia similar to naproxen sodium. $^{20}$

\section{Endometriosis}

Endometriosis is a progressive, estrogen-dependent disease characterized by the extrauterine growth of endometriumlike tissue (endometrial glands and stroma) on the peritoneal surfaces of abdominal organs. Retrograde menstruation with subsequent attachment, invasion, and neovascularization is believed to give rise to the endometriotic lesions in women susceptible to attachment and growth of ectopic endometrial tissue.

Estrogen stimulates the growth of human endometrial tissue, and aromatase is key in its biosynthesis. Aromatase activity is not detectable in normal endometrium. Both an intact aromatase gene and the presence of aromatase enzyme activity are essential for growth of ectopic uterine tissue. ${ }^{21}$ Lack of aromatase expression in eutopic endometrium is maintained by binding of an inhibitory transcription factor to the aromatase promoter II. In endometriosis, an aberrantly expressed factor binds to this same promoter, activates aromatase expression, and thus local estrogen biosynthesis. ${ }^{22}$ The aberrantly expressed aromatase in endometriosis is stimulated by PGE-2, resulting in local production of estrogen that induces PGE-2 formation, thereby establishing a positive feedback cycle. ${ }^{23}$ At the same time, deficient expression of 17- $\beta$-hydroxysteroid dehydrogenase type 2 impairs the inactivation of estradiol to estrone. Both favor accumulation of increased estradiol and PGE-2 in the endometrial tissues.

COX-2 is induced in the proliferative stage of the endometrium, and COX-2, rather than COX-1, is the primary isoenzyme involved in the endometrial productions of prostaglandins. Peritoneal PGE-2 in endometriotic stromal cells may also induce steroidogenic acute regulatory protein, further contributing to the development of endometriosis. ${ }^{24}$ Aromatase inhibitors have successfully treated unusually aggressive post-menopausal endometriosis, ${ }^{23}$ and future treatment of endometriosis will likely combine both COX-2 and aromatase inhibitors. At the present time, however, dysmenorrhea, pelvic pain, and dyspareunia, rather than the disease itself, are currently the major indications for both medical and surgical therapies of endometriosis. ${ }^{25}$

\section{COX-2 in ovarian cancer}

COX-2 is involved in critical steps of cancer onset and progression. It is highly inducible by tumor promoters and growth factors, overexpressed in cancer cells, and associated with enhanced proliferative activity, apoptosis inhibition, increased metastatic potential, and neoangiogenesis. ${ }^{26}$

An increase in COX-2 expression may represent an independent prognostic factor associated with malignant transformation and tumorigenesis of epithelial ovarian neoplasms. ${ }^{26}$ COX-2 expression is observed in $78.6 \%$ of ovarian cancers and $66.7 \%$ of borderline malignant tumors. It is significantly higher among cancers than benign cystadenomas. COX-2 expression may also mark sensitivity to platin-based chemotherapy in ovarian cancer in that COX-2, and not COX-1, is expressed in $80 \%$ of unresponsive cases, versus $35.7 \%$ of responsive patients. 26

Selective COX-2 inhibitors have yet to be tested for treating ovarian carcinoma patients. Acetylsalicylic acid, acetaminophen, and a COX-2 inhibitor (NS-398) decreased cell numbers and mitotic activity and increased apoptosis in human ovarian cancer cell lines in vitro. ${ }^{27}$ With continuing progress in gene therapy, the COX-2 gene promoter region might function as a tumor-specific target for gene therapy of ovarian cancer.

\section{Procedural analgesia}

Preoperative administration of analgesics can prevent or reduce hyperalgesia and inhibit inflammation and pain by reducing the synthesis of prostaglandins in response to surgical injury. Neither celecoxib, nor rofecoxib, have an effect on platelets or bleeding time, so they need not be discontinued prior to elective surgery. Preoperative administration of parecoxib is well tolerated, safe and effective. ${ }^{28}$

Postoperatively, propacetamol is well tolerated, and is as efficient against pain as ketorolac. Parecoxib sodium has been shown to be as effective as intravenous ketorolac, and superior to intravenous morphine in women experiencing moderate-to-severe pain after abdominal hysterectomy or myomectomy. ${ }^{29}$

\section{CONCLUSION}

In regard to COX-2 inhibitors, concerns have been raised regarding costs versus benefits. NSAIDs such as diclofenac, naproxen and mefenamic acid have been on the market for over 20 years. They are economical compared with COX-2 inhibitors, so are likely to remain the drug of choice for patients at lesser risk. ${ }^{4}$ However, in obstetrics/gynecology

108 CM\&R 2003:1 (April) Connolly


practice COX-2 inhibitors are likely to play evolving roles in treating abnormal uterine bleeding, endometriosis, ovarian cancer management and/or prevention, and perioperative pain, and thus deserve wider attention and application.

\section{ACKNOWLEDGMENTS}

Thanks to Marshfield Clinic Research Foundation for providing assistance in the preparation of this manuscript through the services of Graig Eldred and Alice Stargardt.

\section{REFERENCES}

1. Urban MK. COX-2 specific inhibitors offer improved advantages over traditional NSAIDs. Orthopedics 2000;23(7 suppl):S761-S764.

2. Phelps W. Overview on clinical data of dexibuprofen. Clin Rheumatol 2001;20(Suppl 1):S15-S21.

3. Weaver AL. Rofecoxib: clinical pharmacology and clinical experience. Clin Ther 2001;23:1323-1338.

4. Gotta AW. Valdecoxib (Pharmacia). Curr Opin Investig Drugs 2002;3:240-245.

5. Simon LS, Weaver AL, Graham DY, Kivitz AJ, Lipsky PE, Hubbard RC, Isakson PC, Verburg KM, Yu SS, Zhao WW, Geis GS. Anti-inflammatory and upper gastrointestinal effects of celecoxib in rheumatoid arthritis: a randomized controlled trial. JAMA 1999;282:1921-1928.

6. Silverstein FE, Faich G, Goldstein JL, Simon LS, Pincus T, Whelton A, Makuch R, Eisen G, Agrawal NM, Stenson WF, Burr AM, Zhao WW, Kent JD, Lefkowith JB, Verburg KM, Geis GS. Gastrointestinal toxicity with celecoxib vs nonsterioidal anti-inflammatory drugs for osteoarthritis and rheumatoid arthritis: the CLASS study: A randomized controlled trial. Celecoxib Long-term Arthritis Safety Study. JAMA 2000;284:1247-1255.

7. White WB, Faich G, Whelton A, Maurath C, Ridge NJ, Verburg KM, Geis GS, Lefkowith JB. Comparison of thromboembolic events in patients treated with celecoxib, a cyclooxygenase- 2 specific inhibitor, versus ibuprofen or diclofenac. Am J Cardiol 2002;89:425-430.

8. Harris RC, McKanna JA, Akai Y, Jacobson HR, Dubois RN, Breyer MD. Cyclooxygenase-2 is associated with the macula densa of rat kidney and increases with salt restriction. J Clin Invest 1994;94:2504-2510.

9. Yang T, Endo Y, Huang YG, Smart A, Briggs JP, Schnermann J. Renin expression in COX-2-knockout mice on normal or low-salt diets. Am J Physiol Renal Physiol 2000;279:F819F825.

10. Swan SK, Rudy DW, Lasseter KC, Ryan CF, Buechel KL, Lambrecht LJ, Pinto MB, Dilzer SC, Obrda O, Sundblad KJ, Gumbs CP, Ebel DL, Quan H, Larson PJ, Schwartz JI, Musliner TA, Gertz BJ, Brater DC, Yao SL. Effect of cyclooxygenase-2 inhibition on renal function in elderly persons receiving a low-salt diet. A randomized, controlled trial. Ann Intern Med 2000;133:1-9.

11. Whelton A. Renal and related cardiovascular effects of conventional and COX-2-specific NSAIDs and non-NSAID analgesics. Am J Ther 2000;7:63-74.

12. Whelton A, Schulman G, Wallemark C, Drower EJ, Isakson PC, Verburg KM, Geis GS. Effects of celecoxib and naproxen on renal function in the elderly. Arch Intern Med 2000;160 1465-1470.
13. Pfister AK, Crisalli RJ, Carter WH. Cyclooxygenase-2 inhibition and renal function. Ann Intern Med 2001;134:1077; author reply 1078 .

14. Dunn MJ. Are COX-2 selective inhibitors nephrotoxic? Am J Kidney Dis 2000;35:976-977.

15. Facchinetti F, Sgarbi L, Piccinini F, Volpe A. A comparison of glyceryl trinitrate with diclofenac for the treatment of primary dysmenorrhea: an open, randomized, cross-over trial. Gynecol Endocrinol 2002;16:39-43.

16. Dawood MY. Nonsteroidal anti-inflammatory drugs and changing attitudes toward dysmenorrhea. Am J Med 1988;84:2329.

17. Mehlisch DR, Fulmer RI. A crossover comparison of bromfenac sodium, naproxen sodium, and placebo for relief of pain from primary dysmenorrhea. J Womens Health 1997;6:83-92.

18. Marchini M, Tozzi L, Bakshi R, Pistai R, Fedele L. Comparative efficacy of diclofenac dispersible $50 \mathrm{mg}$ and ibuprofen $400 \mathrm{mg}$ in patients with primary dysmenorrhea. A randomized, double-blind, within-patient, placebo-controlled study. Int J Clin Pharmacol Ther 1995;33:491-497.

19. Ezcurdia M, Cortejoso FJ, Lanzon R, Ugalde FJ, Herruzo A, Artigas R, Fernandez F, Torres F, Mauleon D. Comparison of the efficacy and tolerability of dexketoprofen and ketoprofen in the treatment of primary dysmenorrhea. J Clin Pharmacol 1998;38(12 suppl):65S-73S.

20. Daniels SE, Talwalker S, Torri S, Snabes MC, Recker DP, Verburg KM. Valdecoxib, a cyclooxygenase-2-specific inhibitor, is effective in treating primary dysmenorrhea. Obstet Gynecol 2002;100:350-358.

21. Fang Z, Yang S, Gurates B, Tamura M, Simpson E, Evans D, Bulun SE. Genetic or enzymatic disruption of aromatase inhibits the growth of ectopic uterine tissue. J Clin Endocrinol Metab 2002;87:3460-3466.

22. Yang S, Fang Z, Suzuki T, Sasano H, Zhou J, Gurates B, Tamura M, Ferrer K, Bulun S. Regulation of aromatase P450 expression in endometriotic and endometrial stromal cells by CCAAT/enhancer binding proteins (C/EBPs): decreased $\mathrm{C} / \mathrm{EBPbeta}$ in endometriosis is associated with overexpression of aromatase. J Clin Endocrinol Metab 2002;87:23362345.

23. Bulun SE, Gurates B, Fang Z, Tamura M, Sebastian S, Zhou J, Amin S, Yang S. Mechanisms of excessive estrogen formation in endometriosis. J Reprod Immunol 2002;55:21-33.

24. Tsai SJ, Wu MH, Lin CC, Sun HS, Chen HM. Regulation of steroidogenic acute regulatory protein expression and progesterone production in endometriotic stromal cells. J Clin Endocrinol Metab 2001;86:5765-5773.

25. Chwalisz K, Garg R, Brenner RM, Schubert G, Elger W. Selective progesterone receptor modulators (SPRMs): a novel therapeutic concept in endometriosis. Ann N Y Acad Sci 2002;955:373-388.

26. Denkert C, Köbel M, Pest S, Koch I, Berger S, Schwabe M, Siegert A, Reles A, Klosterhalfen B, Hauptmann S. Expression of cyclooxygenase 2 is an independent prognostic factor in human ovarian carcinoma. Am J Pathol 2002;160:893-903.

27. Rodríguez-Burford C, Barnes MN, Oelschlager DK, Myers RB, Talley LI, Partridge EE, Grizzle WE. Effects of nonsteroidal anti-inflammatory agents (NSAIDs) on ovarian carcinoma cell lines: preclinical evaluation of NSAIDs as chemopreventive agents. Clin Cancer Res 2002;8:202-209. 
28. Desjardins PJ, Grossman EH, Kuss ME, Talwalker S, Dhadda S, Baum D, Hubbard RC. The injectable cyclooxygenase-2specific inhibitor parecoxib sodium has analgesic efficacy when administered preoperatively. Anesth Analg 2001;93:721-727.

29. Barton SF, Langeland FF, Snabes MC, LeComte D, Kuss ME, Dhadda SS, Hubbard RC. Efficacy and safety of intravenous parecoxib sodium in relieving acute postoperative pain following gynecologic laparotomy surgery. Anesthesiology 2002;97:306-314 